\title{
Investigation of microwave and electrical characteristics of Co-Zr substituted M-type Ba-Sr hexagonal ferrite
}

\author{
Lovdeep Singh ${ }^{1,3}$, Jagjeet Malhotra ${ }^{1}$, Charanjeet Singh ${ }^{2,3 *}$, S. Bindra Narang ${ }^{2}$, \\ MADHU CHANDRA ${ }^{4}$ \\ ${ }^{1}$ Department of Electronics and Communication Engineering, D.A.V. Institute of Engineering and Technology, \\ Jalandhar, Punjab, India \\ ${ }^{2}$ Department of Electronics Technology, Guru Nanak Dev University, Amritsar, Punjab, India \\ ${ }^{3}$ Department of Electronics and Communication Engineering, Rayat Bahra Institute of Engineering and Nanotechnology, \\ Hoshiarpur, Punjab, India \\ ${ }^{4}$ Department of Microwave Engineering and Electromagnetic Theory, Chemnitz University of Technology, \\ Chemnitz, Germany
}

\begin{abstract}
Microwave characteristics of M-type hexagonal ferrite, $\mathrm{Ba}_{0.5} \mathrm{Sr}_{0.5} \mathrm{Co}_{\mathrm{x}} \mathrm{Zr}_{\mathrm{x}} \mathrm{Fe}_{(12-2 \mathrm{x})} \mathrm{O}_{19}(\mathrm{x}=0.0$ to 1.0 in steps of 0.2), have been investigated as a function of frequency and substitution at X-band. The microwave absorption has been investigated using absorber testing device method. The static I-V characteristics have been studied as a function of substitution. The results show maximum microwave absorption at higher substitution. The static current exhibits ohmic behavior from 0 to $3 \mathrm{~V}$ and exponential trend from 3 to $4.8 \mathrm{~V}$. The microstructure influences both microwave and electrical properties. The ferrite compositions for different electromagnetic applications are also suggested by measuring the microwave absorbed, transmitted and reflected power.
\end{abstract}

Keywords: ferrites; microwave properties; electrical properties

(C) Wroclaw University of Technology.

\section{Introduction}

Electromagnetic pollution is exponentially increasing due to the unprecedented increase in the speed of digital devices and wireless communications. The absorption of electromagnetic signal is required to combat this problem, and ferrites are being used as microwave absorbers/electromagnetic shields [1,2]. These absorbers are incorporated in the enclosures of electronic devices, placed around known or potential sources of EMI, in shields around cables, to reduce common-mode currents, in noise filters as well as in applications, such as anechoic chambers, shielding radar radiation, radar absorbing materials (RAM), stealth technology, etc. The frequency range of application of extensively used spinel ferrites is governed by Snoek's law and limited to few

*E-mail: charanjeet2003@ rediffmail.com gigahertz. However, hexagonal ferrites can be engineered for absorber applications from microwave to higher frequencies [3-8].

In this manuscript, we are investigating microwave and electrical characteristics of $\mathrm{Co}-\mathrm{Zr}$ substituted M-type hexagonal $\mathrm{Ba}_{0.5} \mathrm{Sr}_{0.5} \mathrm{Co}_{\mathrm{x}} \mathrm{Zr}_{\mathrm{x}} \mathrm{Fe}_{(12-2 \mathrm{x})} \mathrm{O}_{19}$ ferrite. The expected correlation between microstructure and reported parameters is also discussed.

\section{Experimental}

The microwave characteristics of $\mathrm{M}$ type ferrite, $\quad \mathrm{Ba}_{0.5} \mathrm{Sr}_{0.5} \mathrm{Co}_{\mathrm{x}} \mathrm{Zr}_{\mathrm{x}} \mathrm{Fe}_{(12-2 \mathrm{x})} \mathrm{O}_{19}$, have been studied as a function of substitution and frequency at X-band. Synthesis and characterization of this ferrite has been reported by Charanjeet et al. [9]. The ferrites with $\mathrm{x}=0.0,0.2,0.4,0.6,0.8$ and 1.0 were studied and the reflection loss was measured 
by absorber testing device (ATD) method [10, 11]. The microwave frequency source generated Xband frequencies of 8 to $12.4 \mathrm{GHz}$ in a slotted rectangular waveguide. The reflection loss, RL, was measured using power meter, Tektronix-Model 3320. The microwave power was supplied to ferrite sample with different compositions, backed by a metallic plate in the waveguide, and the reflected power was measured with and without the sample. The reflection loss was determined from the difference between the two reflected powers and it was proportional to the power absorbed.

The reflection loss, RL, was calculated using following relation:

$$
R L(d B)=10 \log _{10}\left(P_{r} / P_{i}\right)
$$

where $P_{r}$ is the power reflected from the sample backed by the metal plate and $\mathrm{P}_{\mathrm{i}}$ is the power reflected from the metallic plate without the sample.

The large reflection loss corresponds to higher absorption and vice versa. The reflection loss of $-10 \mathrm{~dB}$ corresponds to $90 \%$ absorption. We are reporting the results by selecting the thickness of composition in which microwave absorption is the highest, the thicknesses are as follows: $\mathrm{x}=0.0$ at $3.5 \mathrm{~mm}, \mathrm{x}=0.2$ at $3.4 \mathrm{~mm}, \mathrm{x}=0.4$ at $3.6 \mathrm{~mm}$, $\mathrm{x}=0.6$ at $3.5 \mathrm{~mm}, \mathrm{x}=0.8$ at $3.5 \mathrm{~mm}, \mathrm{x}=1.0$ at $4.6 \mathrm{~mm}$. The term matching frequency, used in the manuscript, stands for maximum power absorption at a particular frequency.

For current (I)-voltage (V) measurements, samples with different compositions were coated with silver paste on both the sides. The voltage was applied using copper electrodes in the sample holder. The current measurements were carried out using Keithley electrometer, model 6514.

\section{Results and discussion}

\subsection{Microwave absorption}

The composition can act as an absorber, reflector or transmitter at a particular frequency depending on whether the microwave signal is absorbed, reflected or transmitted as shown in Fig. 1.

The graph in Fig. 2 displays variation of reflection loss or microwave absorption as
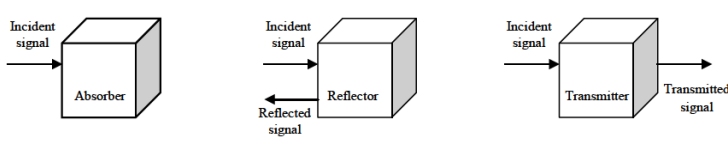

Fig. 1. Ferrite samples with different compositions as absorber, reflector and transmitter.

a function of frequency and substitution of $\mathrm{Co}^{2+}$ and $\mathrm{Zr}^{4+}$ ions. The microwave absorption is small at lower substitution and increases at higher substitution. All compositions have maxima or minima at the same frequency. For composition $\mathrm{x}=0.0\left(\mathrm{Ba}_{0.5} \mathrm{Sr}_{0.5} \mathrm{Fe}_{12} \mathrm{O}_{19}\right)$, reflection loss attains a value of $-8.25 \mathrm{~dB}$ at $9 \mathrm{GHz}$ in low frequency region, which is the maximum value observed for this composition in the whole frequency region. For composition $\mathrm{x}=0.2$ $\left(\mathrm{Ba}_{0.5} \mathrm{Sr}_{0.5} \mathrm{Co}_{0.2} \mathrm{Zr}_{0.2} \mathrm{Fe}_{11.6} \mathrm{O}_{19}\right)$, the $\mathrm{RL}$ remains lower than in other compositions at the corresponding frequencies except at 11.6 and $8.4 \mathrm{GHz}$, with the maximum value of $-6.02 \mathrm{~dB}$ at $9 \mathrm{GHz}$.

For the compositions with $\mathrm{x}=0.4$ and $\mathrm{x}=0.6, \quad\left(\mathrm{Ba}_{0.5} \mathrm{Sr}_{0.5} \mathrm{Co}_{0.4} \mathrm{Zr}_{0.4} \mathrm{Fe}_{11.2} \mathrm{O}_{19} \quad\right.$ and $\left.\mathrm{Ba}_{0.5} \mathrm{Sr}_{0.5} \mathrm{Co}_{0.6} \mathrm{Zr}_{0.6} \mathrm{Fe}_{10.8} \mathrm{O}_{19}\right)$, the largest values of $\mathrm{RL}$ are again observed at $9 \mathrm{GHz}$, achieving $-9.04 \mathrm{~dB}$ and $-10.77 \mathrm{~dB}$, respectively. For the composition $\mathrm{x}=0.8$ $\left(\mathrm{Ba}_{0.5} \mathrm{Sr}_{0.5} \mathrm{Co}_{0.8} \mathrm{Zr}_{0.8} \mathrm{Fe}_{10.4} \mathrm{O}_{19}\right)$, RL approaches its maximum value of $-13.91 \mathrm{~dB}$ at $9 \mathrm{GHz}$. This composition exhibits the highest RL among all the compositions. For composition $\mathrm{x}=1.0$ $\left(\mathrm{Ba}_{0.5} \mathrm{Sr}_{0.5} \mathrm{CoZrFe}_{10} \mathrm{O}_{19}\right)$, RL acquires a maximum value of $-11.43 \mathrm{~dB}$ at $9 \mathrm{GHz}$ and a minimum of $-1.12 \mathrm{~dB}$ at $8.4 \mathrm{GHz}$, which is the lowest value along the entire frequency range among all the compositions.

Table 1 shows the variation of various electromagnetic parameters as a function of frequency and substitution of $\mathrm{Co}^{2+}$ and $\mathrm{Zr}^{4+}$ ions. The maximum absorbed power, $95.9 \%$, is observed in the composition $\mathrm{x}=0.8$, while it is minimum in the composition $\mathrm{x}=0.2$. All the compositions show maximum absorbed power at a matching frequency of $9 \mathrm{GHz}$ in the low frequency region. The maximum absorbed and reflected power increases non-linearly with the substitution of $\mathrm{Co}^{2+}$ and $\mathrm{Zr}^{4+}$ ions. 


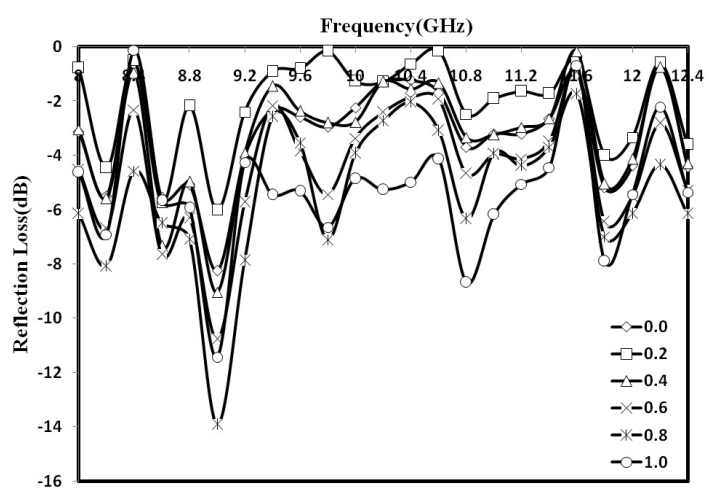

Fig. 2. The variation of reflection loss as a function of frequency and substitution in $\mathrm{Ba}_{0.5} \mathrm{Sr}_{0.5} \mathrm{Co}_{x} \mathrm{Zr}_{x} \mathrm{Fe}_{(12-2 x)} \mathrm{O}_{19}$ ferrite $\quad(\mathrm{x}=$ $0.0,0.2,0.4,0.6,0.8,1.0)$.

The maximum reflected power of $97.3 \%$ was registered at $8.4 \mathrm{GHz}$ for the composition $\mathrm{x}=1.0$ and the minimum of $67 \%$ was observed for the composition $\mathrm{x}=0.8$ at $11.6 \mathrm{GHz}$. Thus, the composition 1.0 reflects nearly all microwave signal falling on it.

\subsection{Transmitted power}

When the composition sample, backed by a metal plate, is placed in a waveguide, the signal can be reflected from the plate and/or the composition sample. To find out whether the signal is reflected from the plate and/or the composition sample, maximum power, $\mathrm{P}_{\text {tmax }}$, transmitted through the composition is measured. If (i) $\mathrm{P}_{\mathrm{rmax}}$ and $\mathrm{P}_{\mathrm{tmax}}$ in a composition occur at the same frequency, the reflected signal comes from the plate only and it passes through the composition without absorption (ii) $\mathrm{P}_{\text {rmax }}$ and $\mathrm{P}_{\text {tmax }}$ do not occur at the same frequency, the signal is reflected from both the plate and the composition.

The composition $\mathrm{x}=0.2$ shows the highest transmitted power (approx. $100 \%$ ) in comparison to other compositions (Table 1). Furthermore, it satisfies the first condition, i.e. $\mathrm{P}_{\mathrm{rmax}}$ and $\mathrm{P}_{\mathrm{tmax}}$ occur at the same frequency $(10.6 \mathrm{GHz})$, which shows that almost entire microwave signal is transmitted through it without absorption. However, all other compositions agree with the second condition, implying that the signal is reflected from both the plate and composition. The maximum transmitted power occurs in the middle frequency region in all the compositions.

\subsection{Snapshots}

The snapshots for different compositions from a cathode ray oscilloscope (CRO) screen at different frequencies, which are presented in Fig. 3, show the input signal incident on the composition and the signal after passing through it. It is observed that the ferrite compositions only change the amplitude of the signal, while they do not change other characteristics viz. frequency and phase of the signal. Consequently, the ferrite compositions do not distort the signal passing through them.
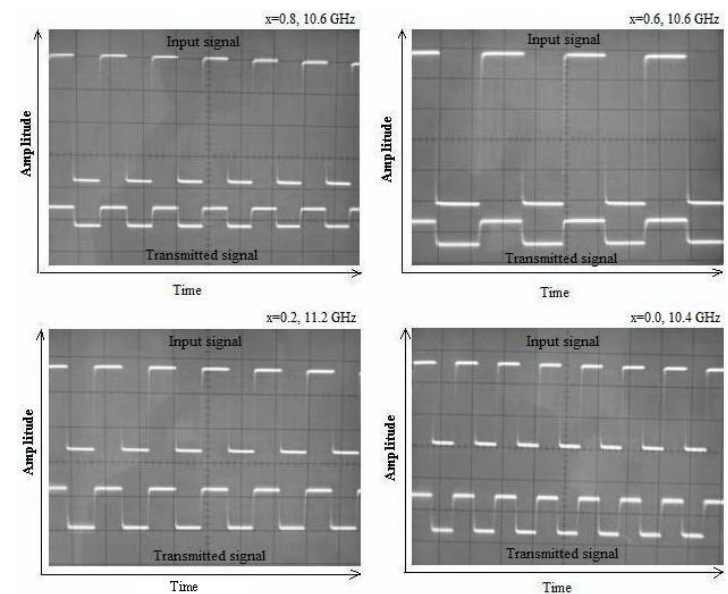

Fig. 3. Snapshots of input signal and signal transmitted through a composite sample (amplitude value of the signal is a guide to the eye).

Fig. 4 shows the scanned electron micrographs of ferrite compositions reported in a previous paper [9]. We have already discussed that maximum microwave absorption takes place at higher substitution ( $\mathrm{x}=0.8$ and 1.0). It has been attributed to the good intergrain connectivity and an increase in grain size with substitution $\mathrm{Co}^{2+}$ and $\mathrm{Zr}^{4+}$ ions, as shown in the micrographs. The grain connectivity eases the flow of the microwave field across the grains and the increase in grain size increases the conductive grain volume at higher substitution. Furthermore, the number of grain boundaries is reduced with substitution as exhibited in the micrographs and these grain boundaries offer high resistivity for charge cariers to flow [12]. These 
Table 1. The variation of maximum absorbed power, maximum reflected power and maximum transmitted power as function of frequency and composition $\mathrm{x}$.

\begin{tabular}{cccc}
\hline $\begin{array}{c}\text { Composition } \\
\mathrm{x}\end{array}$ & $\begin{array}{c}\text { Maximum absorbed } \\
\text { power }(\%) / \text { frequency }\end{array}$ & $\begin{array}{c}\text { Maximum reflected } \\
\text { power }(\%) / \text { frequency }\end{array}$ & $\begin{array}{c}\text { Maximum transmitted } \\
\text { power }(\%) / \text { frequency }\end{array}$ \\
\hline \hline 0.0 & $85.0-9 \mathrm{GHz}$ & $87.1-12.2 \mathrm{GHz}$ & $32.4-10.4 \mathrm{GHz}$ \\
0.2 & $75.0-9 \mathrm{GHz}$ & $96.8-10.6 \mathrm{GHz}$ & $99.5-10.6 \mathrm{GHz}$ \\
0.4 & $87.5-9 \mathrm{GHz}$ & $96.2-11.6 \mathrm{GHz}$ & $30.5-10.4 \mathrm{GHz}$ \\
0.6 & $91.6-9 \mathrm{GHz}$ & $80.5-11.6 \mathrm{GHz}$ & $19.1-10.6 \mathrm{GHz}$ \\
0.8 & $95.9-9 \mathrm{GHz}$ & $67.0-11.6 \mathrm{GHz}$ & $19.0-10.6 \mathrm{GHz}$ \\
1 & $92.8-9 \mathrm{GHz}$ & $97.3-8.4 \mathrm{GHz}$ & $4.76-10.6 \mathrm{GHz}$ \\
\hline
\end{tabular}

factors altogether increase the microwave absorption at higher substitution.

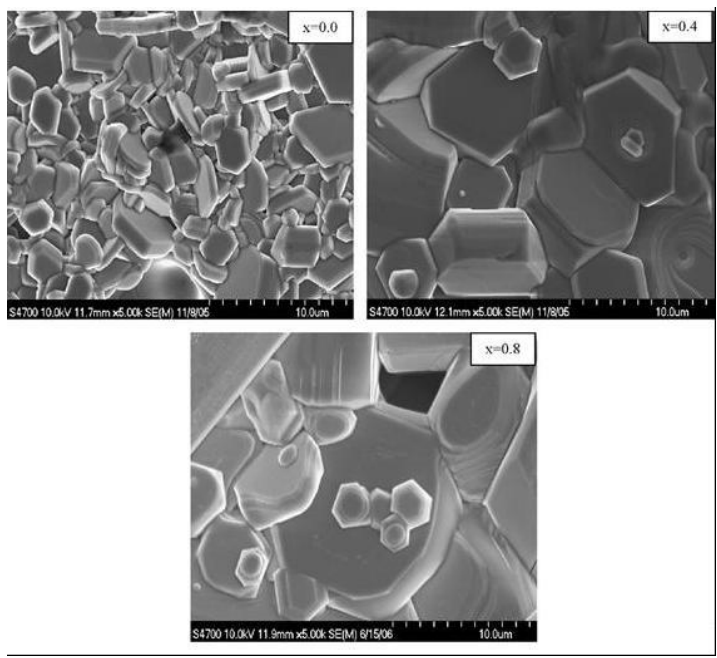

Fig. 4. SEM micrographs of compositions with $\mathrm{x}=0.0$, 0.4 and 0.8 .

\subsection{Current-voltage relationship}

The plots of static current vs. voltage in Fig. 5 display that all the compositions (except $\mathrm{x}=0.2$ ) show nearly ohmic behavior up to $3 \mathrm{~V}$, where the current starts rising exponentially. The compositions $\mathrm{x}=0.0,0.4$ and 0.8 have nearly the same current along the entire applied voltage: the current is about $13 \mu \mathrm{A}$ at $3 \mathrm{~V}$ which rises to $78 \mu \mathrm{A}$ at $4.8 \mathrm{~V}$ and gives the resistance of $180 \mathrm{k} \Omega$ in the ohmic region. For compositions $\mathrm{x}=0.6$ and 1.0, nearly the same current is observed in the ohmic as well as non ohmic region. It is $10.3 \mu \mathrm{A}$ at $3 \mathrm{~V}$ and increases to $60 \mu \mathrm{A}$ at $4.8 \mathrm{~V}$. Both of these compositions show a resistance of $250 \mathrm{k} \Omega$ up to $3 \mathrm{~V}$.

The composition with 0.2 exhibits a nearly constant current of $3.5 \mathrm{nA}$ throughout the whole applied voltage range. It is connected with the high resistance of $500 \mathrm{M} \Omega$ which opposes the flow of current across it.

The conduction mechanism in ferrites is due to hopping of electrons between $\mathrm{Fe}^{2+}$ and $\mathrm{Fe}^{3+}$ ions at octahedral sites [13]. In other words, the composition 0.2 has less number of free electrons available for hopping between $\mathrm{Fe}^{2+}$ and $\mathrm{Fe}^{3+}$ ions due to high resistance. Similarly, when a microwave signal is applied to it, then the less number of electrons available for hopping between $\mathrm{Fe}^{2+}$ and $\mathrm{Fe}^{3+}$ ions causes minimum absorption of signal. Thus, most of the signal is transmitted through the composition without absorption and the highest microwave power (Table 1) transmitted in this composition confirms this explanation. Therefore, static properties (electrical) and dynamic properties (microwave) in the composition $\mathrm{x}=0.2$ are in agreement with each other.

As discussed before, the intergrain connectivity is improved with the substitution of $\mathrm{Co}^{2+}$ and $\mathrm{Zr}^{4+}$ ions (Fig. 4); this eases the flow of the applied field across it. However, the strength of $\mathrm{Fe}^{3+}$ ions, thus, hopping and conduction, is maximum in composition $\mathrm{x}=0.0$ and minimum in composition $\mathrm{x}=$ 1.0. The competition between the two factors (grain connectivity and electron hopping) causes non linear variation of current with the substitution. The highest current in the composition $\mathrm{x}=0.0$, despite 


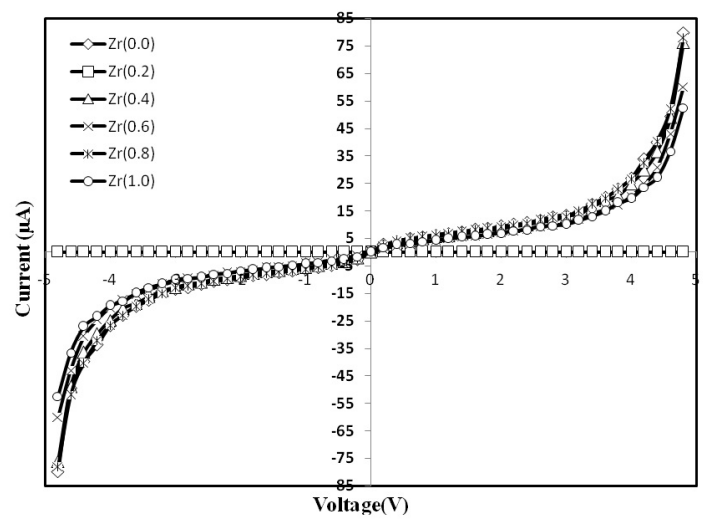

Fig. 5. Current-voltage (I-V) graph as a function of substitution in $\mathrm{Ba}_{0.5} \mathrm{Sr}_{0.5} \mathrm{Co}_{\mathrm{x}} \mathrm{Zr}_{x} \mathrm{Fe}_{(122 \mathrm{x})} \mathrm{O}_{19}$ ferrite $(\mathrm{x}=0.0,0.2,0.4,0.6,0.8,1.0)$.

of poor grain connectivity, is due to the presence of maximum number of $\mathrm{Fe}^{3+}$ ions involved in electron hopping with $\mathrm{Fe}^{2+}$ ions.

\section{Conclusions}

(i) Microwave absorption or RL increases nonlinearly with substitution of $\mathrm{Co}^{2+}$ and $\mathrm{Zr}^{4+}$ ions. All the compositions exhibit maximum microwave absorption in the low frequency region at $9 \mathrm{GHz}$.

(ii) Composition $\mathrm{x}=0.8$, $\mathrm{Ba}_{0.5} \mathrm{Sr}_{0.5} \mathrm{Co}_{0.8} \mathrm{Zr}_{0.8} \mathrm{Fe}_{10.4} \mathrm{O}_{19}$, has $95.9 \%$ absorption with the highest reflection loss of $-13.91 \mathrm{~dB}$ at the matching frequency of $9 \mathrm{GHz}$ and thickness of $3.5 \mathrm{~mm}$, making it suitable for microwave absorber application.

(iii) Composition $\mathrm{x}=0.2$, $\mathrm{Ba}_{0.5} \mathrm{Sr}_{0.5} \mathrm{Co}_{0.2} \mathrm{Zr}_{0.2} \mathrm{Fe}_{11.6} \mathrm{O}_{19}$, can be used for high frequency lossless applications with $99.5 \%$ transmitted power at $10.6 \mathrm{GHz}$.

(iv) Composition $\mathrm{x}=1.0$, $\mathrm{Ba}_{0.5} \mathrm{Sr}_{0.5} \mathrm{CoZrFe}_{10} \mathrm{O}_{19}$, has $97.3 \%$ reflected power at $8.4 \mathrm{GHz}$, giving the possibility for electromagnetic shielding applications.

(v) In all compositions (except $x=0.2$ ), the static electrical current is ohmic at low applied field $(0$ to $3 \mathrm{~V})$ and follows non-linear trend from 3 to $4.8 \mathrm{~V}$.

(vi) Microwave absorption varies in accordance with microstructure due to reduction in grain boundaries, increase in grain connectivity and grain conduction volume with substitution.

\section{Acknowledgements}

We are thankful to S. Gurvinder Singh Bahra (Chairman, Rayat-Bahra Group of Institutes), S. Nirmal Singh Rayat (President, Rayat-Bahra Group of Institutes), Dr. Daljit Singh Bawa (Campus Director) and Dr. Subhash Chander Sharma (Director/Principal) for providing experimental facilities to investigate our work at Rayat-Bahra Institute of Engineering and Nanotechnology, Hoshiarpur, Punjab, India.

\section{References}

[1] Kitaytsev A.A., Koledintseva M.Y., Shinkov A.A., IEEE International Symposium on Electromagnetic Compatibility, 1 (1998), 578.

[2] KitaytseV A.A., Koledintseva M.Y., IEEE Transactions on Electromagnetic Compatibility, 41 (1999), 15.

[3] Koledintseva M.Y., Mikhailovsky L.K., KITAYTSEV A.A., IEEE International Symposium on Electromagnetic Compatability, 2 (2000), 773.

[4] Charanjeet S., NARAng B.S., Vikramuit S., KotNALA R.K., IEEE 15th International Symposium on Antenna Technology and Applied Electromagnetics (ANTEM), Toulouse, France 978-1-4673-0292$0 / 12 / \$ 31.00$ (2012).

[5] Charanjeet S., NARAng B.S., Hudiara I.S., IEEE $X X X$ General Assembly and Scientific Symposium of the International Union of Radio Science (URSI), Istanbul, Turkey 978-1-4244-5118-0/11/\$26.00@(2011) E7-8.

[6] Charanjeet S., NARAng B.S., Hudiara I.S., Koledintseva M.Y., Kitaitsev A.A., Asia-Pacific Radio Science Conference (AP-RASC'10), Toyama, Japan (2010), E4.

[7] Koledintseva M.Y., Ravva P.C., DrewniaK J.L., KitAitseV A.A., Shinkov A.A., IEEE International Symposium on Electromagnetic Compatability, 3 (2006), 598.

[8] Kitaytsev A.A., Koledintseva M.Y., Konkin V.A, CHEPARIN V.P, SHINKOV A.A., International Symposium on Electromagnetic Compatibility, 1999 (1999) 405.

[9] Charanjeet S., Narang B.S., Hudiara I.S., Bai Y., J. Alloy. Compd., 464 (2008), 429.

[10] Meshram M.R., Agrawal N.K., Sinha B., Misra P.S., J. Magn. Magn. Mater., 271 (2004), 207.

[11] Singh P., Babbar V.K., Razdan A., Puri R.K., T. C. Goel T.C., J. Appl. Phys., 87 (2000) 4362.

[12] Zahi S., Hashim M., Daud A.R., J. Magn. Magn. Mater., 308 (2007), 177.

[13] Van Uitert L.G., J. Chem. Phys., 23 (1955), 1883. 